\title{
Detection: From Electrochemistry to Spectroscopy with Chromatographic Techniques, Recent Trends with Nanotechnology
}

\author{
Tawfik A. Saleh \\ Department of Chemistry, King Fahd University of Petroleum \& Minerals, Dhahran, Saudi Arabia \\ Email: tawfikas@hotmail.com
}

Received 8 August 2014; revised 5 September 2014; accepted 8 October 2014

Academic Editor: Binbin Weng, University of Oklahoma, USA

Copyright (C) 2014 by author and Scientific Research Publishing Inc.

This work is licensed under the Creative Commons Attribution International License (CC BY).

http://creativecommons.org/licenses/by/4.0/

(c) () 0 pen Access

\begin{abstract}
The detection of trace levels of chemical, biological and other analytes has many important applications, including industry, forensics and environmental monitoring. Detection Journal is an international journal dedicated to the latest advancement of all areas that are related to detection. Nanotechnology based detection techniques may provide major advantages of low detection limits and rapid testing. This may allow scientists to know early about the case and provide the potential of stopping the problem at earlier stages.
\end{abstract}

\section{Keywords}

Detection, Nanotechnology, Monitoring

\section{Introduction}

The primary goal of this journal is to provide a plat-form for scientists and academicians all over the world to provide, share and discuss various new issues and developments in different aspects of solid-state light sources, sensors devices development, samples' analysis, etc. It aims to determine the state-of-the-art and advances progress in fields related to detection and get through its developments.

\section{Methods for Detection}

\subsection{Nanotechnology for Detection}

Nanotechnology is being exploited in different fields of detection and generally analytical chemistry. The litera-

How to cite this paper: Saleh, T.A. (2014) Detection: From Electrochemistry to Spectroscopy with Chromatographic Techniques, Recent Trends with Nanotechnology. Detection, 2, 27-32. http://dx.doi.org/10.4236/detection.2014.24005 
ture regarding detection has been reviewed with focus on the role of nanotechnology in developing detection techniques. Most of the scientific reports recommend that more investigation should be on electrochemicalbased methods, in addition to the spectroscopic methods where nanotechnology somehow can be involved. I would like to stress that the booming progress in nanotechnology allows much to improve the methods and tools for detection and analysis. Nanotechnology plays a role in development of sensors and biosensors with interest for medicine, water, soil and food industry. The methods of synthesis of nanomaterials can be classified as depicted in Figure 1. The functionalized nanomaterials such as nanotubes, graphene, semiconductors, quantum dots, metal nanoparticles and nanowires, are used as catalytic tools, immobilization platforms or as optical or electro-active labels to improve the sensing performance [1]-[4]. Functionalization of nanomaterials can be performed by several methods. These methods can generally be classified into two categories: covalent and noncovalent functionalization. Figure 2 presents a schematic representation of the classification [1]-[4].

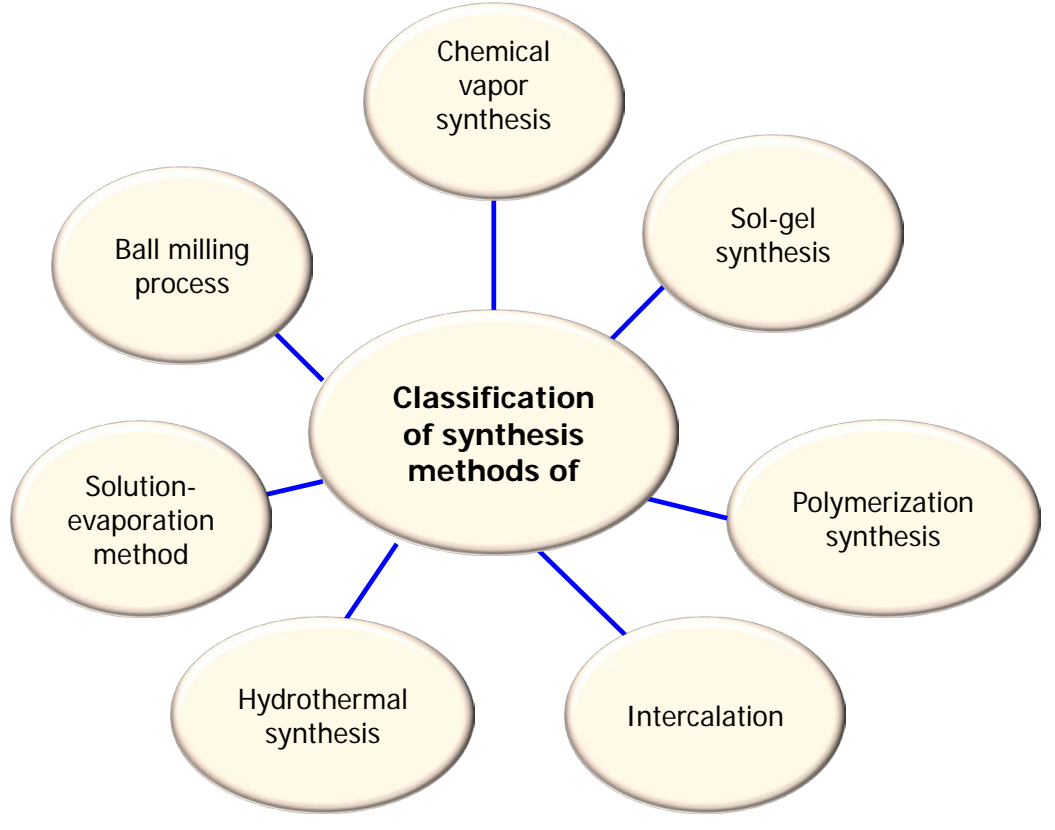

Figure 1. Classification of the methods' synthesis of nanomaterials.

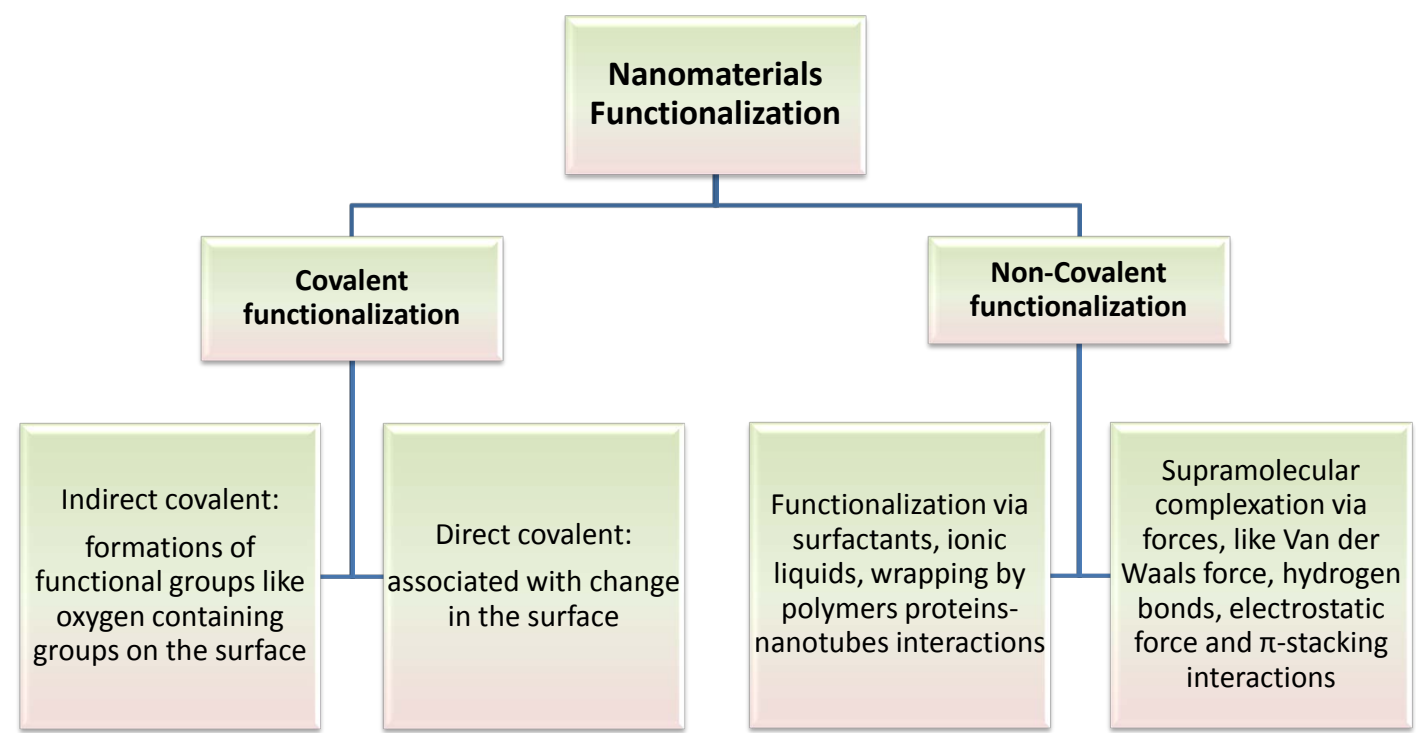

Figure 2. Schematic representation of the methods employed for functionalization of nanomaterials. 


\subsection{Electrochemical Based Methods}

Electrochemical sensor and electrodes using nano-structured materials and nanocomposites are being reported for sensing, detecting and quantifying analytes in liquids or gaseous phases [5] [6]. Recent areas of interest includes bioelectrocatalytic immunosensors based on the dendrimer-associated self-assembled monolayers, protein micropatterning on sensor surfaces for multiplexed analysis, electrochemical response of artificial receptors based on a nanostructured conducting polymer, polypyrrole, or graphene [7] [8]. Because of their ability to act as effective immobilization matrices and electrocatalytic properties, both nano-objects like nanoparticles of metal or metal oxides, quantum dots, carbon nanotubes and graphene; and nanostructured materials like templatebased materials, advanced organic polymers are of high interest for the rational design of bio-functionalized electrodes and related (bio-)sensing systems. Such materials have been reported to improve bioelectrode performance in terms of sensitivity and selectivity (enzymatic biosensors, DNA sensors, immunosensors and cell sensors) or power (biofuel cells) [9] [11].

The research in the field of incorporating nanomaterials into electrochemistry is still of interest to achieve the industrial needs. The future of nanomaterials in electrodes field like biofunctionalized electrodes is expected to move beyond just biosensors or biofuel cells into self-powered sensors and smart sensors that for example can sense and deliver drugs or power a signalling device like theranostic devices. It is required to have better engineer electrode surfaces at the nanoscale for new critical additional functions to the electrodes.

Another area could be of interest is the utilization of nanoparticles as modifiers of the electrodes and as labels. Carbon nanotube-based electrochemical biosensors have been reported as amperometric enzyme electrodes, electrochemical bioaffinity sensors, and carbon carriers for amplified biodetection [12]. Recently, graphenesupported nanocomposites have shown fascinating advantages in electrochemistry for sensor development [13]-[16]. Graphene based enzyme biosensors, graphene based electrochemical DNA sensors, graphene based immunosensors and graphene based enzyme biosensors have been reported in many publications which have been well-documented in recent review articles [17]. For example, grapheme-Au nanocomposites hybrid were synthesized by in situ growth of Au nanoparticles (AuNPs) on the surface of grapheme nanosheets in the presence of poly(diallyldimethylammonium chloride) (PDDA), which improved the AuNPs dispersion and also stabilized cholinesterase with high activity and loading efficiency [18]. Therefore, detection performance of nanomaterial-based detectors has been enhanced in term of sensitivity, limits of detection, and peak capacity, along with various biomedical applications.

\subsection{Spectroscopic Based Methods}

Some of the important areas of research under detection and determination include the enhancement of Raman scattering from molecules adsorbed on nanostructured metal surfaces, known as surface-enhanced Raman scattering (SERS). Substrates can be roughened metal films to highly ordered plasmonic nanostructure assemblies with nanometer-scale control over size, shape, and distance have been fabricated using various lithographic and nonlithographic methods and tested for the trace-level detection of various analytes. Examples include spectroscopic characterization of vibrational modes in artificially designed DNA and nonlinear optical spectroscopy for biomolecular structure at solid-liquid interfaces [19]-[21]. Substrates of gold nanomaterials were reported to enhance the detection limits of human serum albumin through SERS [22]. Immunoelectrochemical detection of protein tumor marker was reported using carbon nanoparticle with cadmium sulfide biotracers [23].

Nanoparticles (NPs) offer biocompatibility, low toxicity, and easy modification of thier structures to incorporate biofunctionality. Such properties in addition to optical properties of nanoparticles make them useful for a wide range of applications such as sensing. The color change of gold nanoparticles, for example, makes them useful for various biological detections [24]. Silver nanoparticles have good chemical stability and conductivity, and excellent optical properties that are extraordinarily efficient at absorbing and scattering light. Thus, silver is extensively investigated for several applications including metal enhanced fluorescence and surface enhanced Raman scattering, which can be used for colorimetric detection and quantification of targets [25]. Magnetic nanoparticles, such as iron, nickel, and cobalt, display excellent conductivity and are often used to concentrate samples. Iron oxide has been utilized as a contrast agent in magnetic resonance imaging as well as the immunomagnetic separation and detection of, numerous pathogens. Research is required to develop improved ways to produce magnetic nanoparticles focusing on ensuring precise composition, uniform surface modification, and reproducible functionalization [25]. 
Fluorescent quantum dots (QDs), of a semiconductor core such as cadmium, mixed with selenium or tellurium, surrounded by a semiconductor outer shell, often zinc sulphide, and a layer of polymer to stabilize the QD, and allow for (bio-)chemical functionalization, are of unique optical properties when compared to conventional semiconductors, organic fluorescent dyes, and proteins. QDs offer excellent photostability and tunable emission spectra from the ultraviolet to the near infrared region, simply by modulating their size. Due to their photostability, QDs avoid the problems of self-absorption, self-fluorescence, and photobleaching from which traditional fluorophores suffer. Therefore, QDs offer applications within many different areas, including waterborne pathogen detection [26].

Polymeric nanoparticles encapsulate a fluorophore within a polymeric coating like fluorescent silica nanoparticles have been applied for detection using fluorescence spectrometers or fluorescent reading microtiter plate readers, as well as in flow cytometry. The protection of the fluorophore by the polymer provides high stability under a range of conditions proving superior to organic dyes in terms of photostability and versatility [27].

\subsection{Chromatography in Detection}

The introduction of nanotechnology in chromatography like liquid chromatography/mass spectrometry (LC-MS) and capillary electrophoresis/mass spectrometry (CE-MS) has resulted in new findings in the study of DNA adduct formation caused by carcinogenic substances, including anticancer drugs. Sample handling and introduction also can benefit from nanotechnology. By emergence of nanotechnology, several analysis techniques are being improved; single cell analysis, in chip/micro machined devices, hyphenated technology and sampling techniques.

Methods where nanomaterials are used with chromatography for the enhancement of separation and thus analysis are also of recent interest. Solid-phase extraction by packed multi-walled carbon nanotubes, followed by LC-MS were reported for the determination of drugs including $\beta$-blockers and non-steroidal anti-inflammatory drugs. High extraction efficiency was reported for most drugs, which is explained due to the large specific surface area and high adsorption capacity of this nanomaterial compared with other conventional solid-phase extraction sorbents [28]. Seeking for possible separation and characterization of small quantities is another area of interest. Nano CE, a suitable technique for samples that may be difficult to separate by nano-liquid chromatography, is employed especially in proteomics and genomics and it has gained increasing importance. Detection of drugs at low concentration and analyses of proteins and nucleic acids at low levels can be achieved using chip based nano-liquid chromatography and nano-capillary [29]. Secretory vesicles can be chemically and individually analyzed with a combination of optical trapping, capillary electrophoresis separation, and laser induced fluorescence detection.

Paper chromatography (PC) has found many applications in biology and biotechnology. For example, gold and silver nanoparticles were reported to detect protein bands after the PC method. PC was performed on a solution containing bovine serum albumin protein. Then, the gold and silver nanoparticles were exploited for paper coloration. It was reported that location of the protein bands was clearly distinct and detectable with this technique [30]. Nanotechnology contributes in the recent research related to chromatography instrumental design. For example, battery-operated nano-flow pumping system with a stop-flow injector has been reported and integrated with an on-column UV-absorption detector that was reduced in LC size to an acceptable weight and power usage for field operation [31]. A detection technique for ion suppression in LC-MS has been reported by adding a probe to LC mobile phase. The probe is so hydrophilic that it is not adsorbed in a reversed-phase nanoflow LC column [32] [33]. More research is expected toward improving the detection limits and toward the design of portable instruments.

\section{Computational}

Computational chemistry is one of the great scientific success stories of the past decades. Modeling and simulation related work would promote understanding the properties of materials and nanomaterials [34]-[37]. Coupling modeling and computational studies with nanotechnology will help develop the nanomaterials designing with required properties that may enhance the detection.

The journal will always be pleased to receive the following types of inputs or submissions, among others: 1) research highlight articles - generally substantial, current review articles that can be expected to be of interest to the detection community; 2) research notes-research announcements; 3) news and views, and "in brief" items_-announcements and news items; and 4) meeting announcements, meeting reports and book reviews. 


\section{Acknowledgements}

The author would like to acknowledge the support provided by King Abdulaziz City for Science and Technology (KACST) through project No. A.T.34-8. The author would also like to acknowledge the support by King Fahd University of Petroleum and Minerals (KFUPM).

\section{References}

[1] Pérez-Lópeza, B. and Merkoçi, A. (2011) Nanomaterials Based Biosensors for Food Analysis Applications. Trends in Food Science \& Technology, 22, 625-639. http://dx.doi.org/10.1016/j.tifs.2011.04.001

[2] Ozdemir, C., Yeni, F., Odaci, D. and Timur, S. (2010) Electrochemical Glucose Biosensing by Pyranose Oxidase Immobilized in Gold Nanoparticle-Polyaniline/AgCl/Gelatin Nanocomposite Matrix. Food Chemistry, 119, 380-385. http://dx.doi.org/10.1016/j.foodchem.2009.05.087

[3] De la Escosura-Muñiz, A. and Merkoçi, A. (2010) Electrochemical Detection of Proteins Using Nanoparticles: Applications to Diagnostics. Expert Opinion on Medical Diagnostics, 4, 21-37. http://dx.doi.org/10.1517/17530050903386661

[4] Aboul-Enein, H.Y. and Ali, I. (2011) Nano Chromatography and Capillary Electrophoresis: Pharmaceutical and Environmental Analyses. Wiley-VCH, Weinheim.

[5] Feng, R., Zhang, Y., Li, H., Wu, D., Xin, X.D., Zhang, S., Yu, H.Q., Wei, Q. and Du, B. (2013) Ultrasensitive Electrochemical Immunosensor for Zeranol Detection Based on Signal Amplification Strategy of Nanoporous Gold Films and Nano-Montmorillonite as Labels. Analytica Chimica Acta, 758, 72-79. http://dx.doi.org/10.1016/j.aca.2012.11.009

[6] Xu, H.-B., Ye, R.-F., Yang, S.-Y., Li, R. and Yang, X. (2014) Electrochemical DNA Nano-Biosensor for the Detection of Genotoxins in Water Samples. Chinese Chemical Letters, 25, 29-34. http://dx.doi.org/10.1016/j.cclet.2013.10.011

[7] Ma, Y., Jiao, K., Yang, T. and Sun, D.X. (2008) Sensitive PAT Gene Sequence Detection by Nano-SiO ${ }_{2} / \mathrm{p}^{-A m i n o t h i-}$ ophenol Self-Assembled Films DNA Electrochemical Biosensor Based on Impedance Measurement. Sensors and Actuators B: Chemical, 131, 565-571. http://dx.doi.org/10.1016/j.snb.2007.12.046

[8] Kim, H.-S. and Yoon, H.C. (2007) Dendrimer-Based Electrochemical Detection Methods.

[9] Ramanaviciene, A., Ramanavicius, A. and Finkelsteinas, A. (2006) Basic Electrochemistry Meets Nanotechnology: Electrochemical Preparation of Artificial Receptors Based on a Nanostructured Conducting Polymer, Polypyrrole. Journal of Chemical Education, 83, 1212. http://dx.doi.org/10.1021/ed083p1212

[10] Li, D., Liu, J.Q., Barrow, C.J. and Yang, W.R. (2014) Protein Electrochemistry Using Graphene-Based Nano-Assembly: An Ultrasensitive Electrochemical Detection of Protein Molecules via Nanoparticle-Electrode Collisions. Chemical Communications, 50, 8197-8200. http://dx.doi.org/10.1039/c4cc03384a

[11] Wang, L., Han, B.X., Dai, L., Li, Y.H., Zhou, H.Z. and Wang, H. (2013) A $\mathrm{La}_{10} \mathrm{Si}_{5} \mathrm{NbO}_{27.5}$ Based Electrochemical Sensor Using Nano-Structured $\mathrm{NiO}$ Sensing Electrode for Detection of $\mathrm{NO}_{2}$. Materials Letters, 109, 16-19. http://dx.doi.org/10.1016/j.matlet.2013.07.032

[12] Walcarius, A., Minteer, S.D., Wang, J., Lin, Y.H. and Merkoçi, A. (2013) Nanomaterials for Bio-Functionalized Electrodes: Recent Trends. Journal of Materials Chemistry B, 1, 4878-4908. http://dx.doi.org/10.1039/c3tb20881h

[13] Baby, T.T., Jyothirmayee Aravind, S.S., Arockiadoss, T., Rakhi, R.B. and Ramaprabhu, S. (2010) Metal Decorated Graphene Nanosheets as Immobilization Matrix for Amperometric Glucose Biosensor. Sensors and Actuators B: Chemical, 145, 71-77.

[14] Chen, Q.W., Zhang, L.Y. and Chen, G. (2012) Facile Preparation of Graphene-Copper Nanoparticle Composite by in Situ Chemical Reduction for Electrochemical Sensing of Carbohydrates. Analytical Chemistry, 84, 171-178. http://dx.doi.org/10.1021/ac2022772

[15] Yang, T., Hu, Y.W., Li, W.J. and Jiao, K. (2011) Single Stranded DNA-Guided Electropolymerization of Polythionine Nanostrip to the Sensing of $\mathrm{H}_{2} \mathrm{O}_{2}$. Colloids and Surfaces B: Biointerfaces, 83, 179-182.

[16] Jiang, L., Gu, S.Q., Ding, Y.P., Ye, D.X., Zhang, Z. and Zhang, F.F. (2013) Amperometric Sensor Based on Tricobalt Tetroxide Nanoparticles-Graphene Nanocomposite Film Modified Glassy Carbon Electrode for Determination of Tyrosine. Colloids and Surfaces B: Biointerfaces, 107, 146-151. http://dx.doi.org/10.1016/j.colsurfb.2013.01.077

[17] Wang, Y., Li, Z.H., Wang, J., Li, J.H. and Lin, Y.H. (2011) Graphene and Graphene Oxide: Biofunctionalization and Applications in Biotechnology. Trends in Biotechnology, 29, 205-212.

[18] Wang, Y., Zhang, S., Du, D., Shao, Y.Y., Li, Z.H., Wang, J., Engelhard, M.H., Li, J.H. and Lin, Y.H. (2011) Self-Assembly of Acetylcholinesterase on a Gold Nanoparticles-Graphene Nanosheet Hybrid for Organophosphate Pesticide Detection Using Polyelectrolyte as a Linker. Journal of Materials Chemistry, 21, 5319-5325.

http://dx.doi.org/10.1039/c0jm03441j 
[19] Sizov, I., Rahman, M., Gelmont, B., Norton, M.L. and Globus, T. (2013) Sub-THz Spectroscopic Characterization of Vibrational Modes in Artificially Designed DNA Monocrystal. Chemical Physics, 425, 121-125. http://dx.doi.org/10.1016/j.chemphys.2013.08.015

[20] Roy, S., Covert, P.A., FitzGerald, W.R. and Hore, D.K. (2014) Biomolecular Structure at Solid-Liquid Interfaces As Revealed by Nonlinear Optical Spectroscopy. Chemical Reviews, 114, 8388-8415. http://dx.doi.org/10.1021/cr400418b

[21] Vithanage, M., Rajapaksha, A.U., Dou, X.M., Bolan, N.S., Yang, J.E. and Ok, Y.S. (2013) Surface Complexation Modeling and Spectroscopic Evidence of Antimony Adsorption on Iron-Oxide-Rich Red Earth Soils. Journal of Colloid and Interface Science, 406, 217-224.

[22] Lin, Z.-H., Chen, I.-C. and Chang, H.-T. (2011) Detection of Human Serum Albumin through Surface-Enhanced Raman Scattering Using Gold "Pearl Necklace” Nanomaterials as Substrates. Chemical Communications, 47, 7116-7118. http://dx.doi.org/10.1039/c1cc11818h

[23] Ho, J.-A.A., Lin, Y.-C., Wang, L.-S., Hwang, K.-C. and Chou, P.-T. (2009) Carbon Nanoparticle-Enhanced Immunoelectrochemical Detection for Protein Tumor Marker with Cadmium Sulfide Biotracers. Analytical Chemistry, 81, 13401346. http://dx.doi.org/10.1021/ac801832h

[24] Upadhyayula, V.K.K. (2012) Functionalized Gold Nanoparticle Supported Sensory Mechanisms Applied in Detection of Chemical and Biological Threat Agents: A Review. Analytica Chimica Acta, 715, 1-18. http://dx.doi.org/10.1016/j.aca.2011.12.008

[25] Ray, P.C., Khan, S.A., Singh, A.K., Senapati, D. and Fan, Z. (2012) Nanomaterials for Targeted Detection and Photothermal Killing of Bacteria. Chemical Society Reviews, 41, 3193-3209. http://dx.doi.org/10.1039/c2cs15340h

[26] Ibanez-Peral, R., Bergquist, P.L., Walter, M.R., Gibbs, M., Goldys, E.M. and Ferrari, B. (2008) Potential Use of Quantum Dots in Flow Cytometry. International Journal of Molecular Sciences, 9, 2622-2638. http://dx.doi.org/10.3390/ijms9122622

[27] Kaittanis, C., Santra, S. and Perez, J.M. (2009) Emerging Nanotechnology-Based Strategies for the Identification of Microbial Pathogenesis. Advanced Drug Delivery Reviews, 62, 408-423. http://dx.doi.org/10.1016/j.addr.2009.11.013

[28] Dahane, S., Gil García, M.D., Martínez Bueno, M.J., Uclés Moreno, A., MartínezGalera, M. and Derdour, A. (2013) Determination of Drugs in River and Wastewaters Using Solid-Phase Extraction by Packed Multi-Walled Carbon Nanotubes and Liquid Chromatography-Quadrupole-Linear Ion Trap-Mass Spectrometry. Journal of Chromatography A, 1297, 17-28. http://dx.doi.org/10.1016/j.chroma.2013.05.002

[29] Sekhon, B.S. (2011) An Overview of Capillary Electrophoresis: Pharmaceutical, Biopharmaceutical and Biotechnology Applications. Journal of Pharmaceutical Education and Research, 2, 2-36.

[30] Ramezani, F. (2012) Protein Bands Detection by Nanoparticles after Paper Chromatography. International Journal of Nanoscience and Nanotechnology, 8, 181-184.

[31] Sharma, S., Plistil, A., Simpson, R.S., Liu, K., Farnsworth, P.B., Stearns, S.D. and Lee, M.L. (2014) Instrumentation for Hand-Portable Liquid Chromatography. Journal of Chromatography A, 1327, 80-89. http://dx.doi.org/10.1016/j.chroma.2013.12.059

[32] Hirabayashi, A., Ishimaru, M., Manri, N., Yokosuka, T. and Hanzawa, H. (2007) Detection of Potential Ion Suppression for Peptide Analysis in Nanoflow Liquid Chromatography/Mass Spectrometry. Rapid Communications in Mass Spectrometry, 17, 2860-2866. http://dx.doi.org/10.1002/rcm.3157

[33] Guetens, G., Van Cauwenberghe, K., De Boeck, G., Maes, R., Tjaden, U.R., van der Greef, J., Highley, M., van Oosterom, A.T. and de Bruijn, E.A. (2000) Nanotechnology in Bio/Clinical Analysis. Journal of Chromatography B: Biomedical Sciences and Applications, 739, 139-150.

[34] Gesquiere, A.J. (2010) Optical Properties and Spectroscopy of Nanomaterials. Journal of the American Chemical Society, 132, 3637-3638.

[35] Heurich, M., Abdul Kadir, M.K. and Tothill, I.E. (2011) An Electrochemical Sensor Based on Carboxymethylated Dextran Modified Gold Surface for Ochratoxin A Analysis. Sensors and Actuators B: Chemical, 156, 162-168. http://dx.doi.org/10.1016/j.snb.2011.04.007

[36] Wei, Z., Sun, Z., Fang, Y., Ren, G., Huang, Y. and Liu, J. (2011) Highly Sensitive Deoxynivalenol Immunosensor Based on a Glassy Carbon Electrode Modified with a Fullerene/Ferrocene/Ionic Liquid Composite. Microchimica Acta, 172, 365-371.

[37] Wang, J. (2005) Nanomaterial-Based Electrochemical Biosensors. Analyst, 130, 421-426. http://dx.doi.org/10.1039/b414248a 
Scientific Research Publishing (SCIRP) is one of the largest Open Access journal publishers. It is currently publishing more than 200 open access, online, peer-reviewed journals covering a wide range of academic disciplines. SCIRP serves the worldwide academic communities and contributes to the progress and application of science with its publication.

Other selected journals from SCIRP are listed as below. Submit your manuscript to us via either submit@scirp.org or Online Submission Portal.
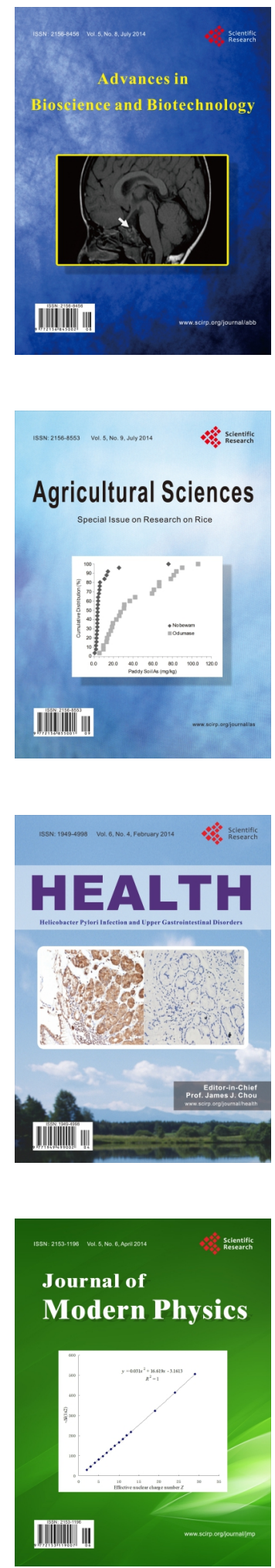
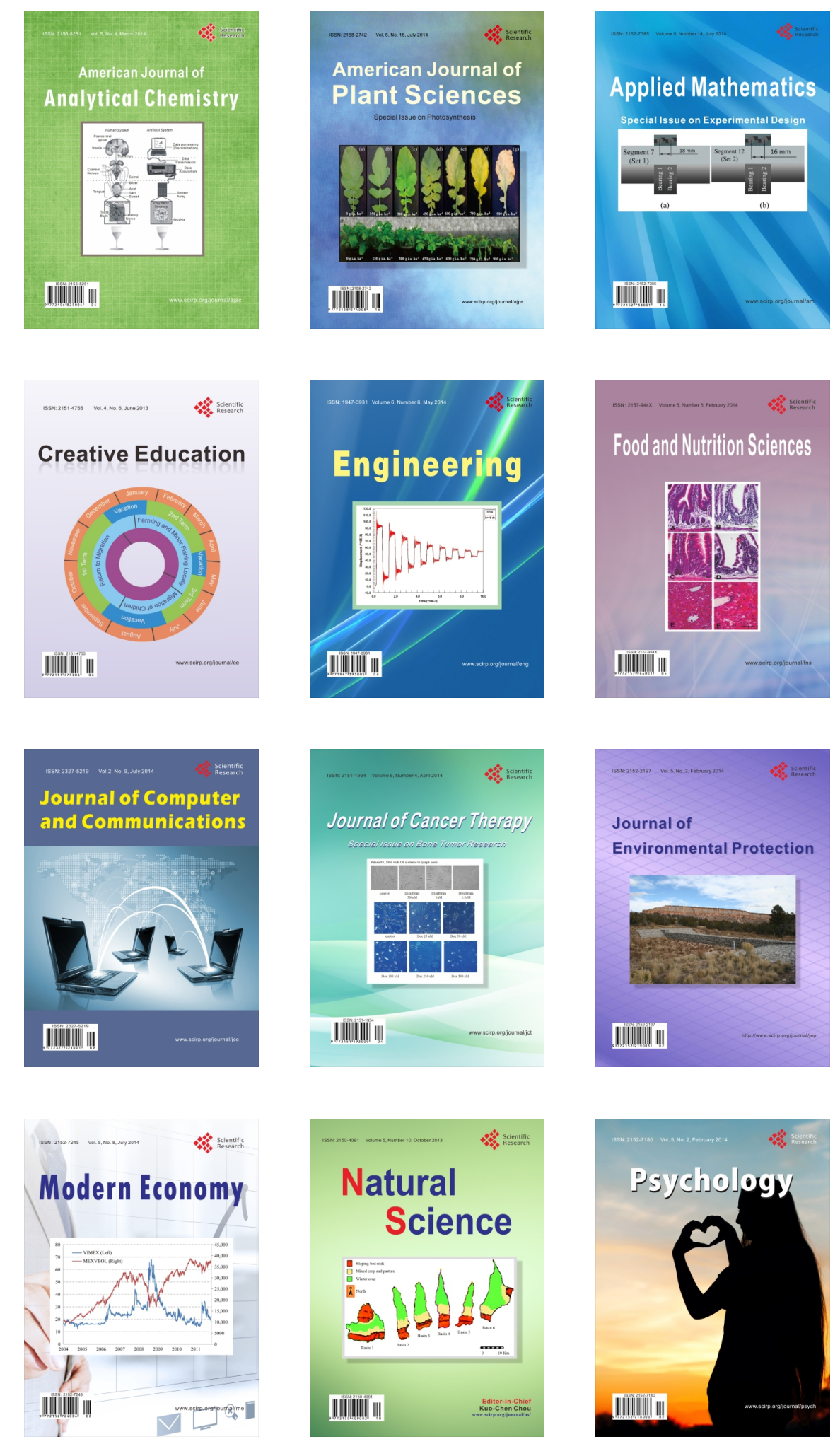